Lance H. Rodan, MD

Maria Zak, NP-Pediatrics

James Stavropoulos, $\mathrm{PhD}$, FCCMG

Ann M. Joseph-George,

$\mathrm{PhD}$, FCCMG

Berge A. Minassian, MD

Neurol Genet

2016;2:e43; doi: 10.1212/

NXG.0000000000000043

\section{CO-OCCURRENCE OF 16P13.11 MICRODELETION AND RING CHROMOSOME 20 SYNDROME \\ OPEN}

A previously healthy 16-year-old girl of Jamaican descent presented with a 1-year history of progressive daytime somnolence, sleep attacks (sudden irresistible episodes of sleep), and paroxysms of altered level of consciousness. Her parents also reported irritability, mood lability, and hyperphagia. Her history was notable for a mild learning disability diagnosed at 9 years of age. Before symptom onset, she attended regular class at school with average academic performance and was independent in instrumental activities of daily living. On examination, she was normocephalic and nondysmorphic and had no focal neurologic deficits.

MRI brain was interpreted as within normal limits. EEG demonstrated periods of diffuse, frontally dominant, semirhythmic delta and theta complexes with sharply contoured morphology (figure, A). These periods were associated clinically with decreased responsiveness and drowsiness. Episodes lasted from 10 to 90 minutes and recurred numerous times throughout the daytime. Initially, episodes occurred once or twice daily, but they increased in frequency over time to an average of 5 times a day. In between episodes, EEG background was normal. The patient was no longer able to attend full days at school, although she remained independent in instrumental activities of daily living.

Conventional G-banding karyotyping of peripheral blood (figure, B) showed an apparently balanced karyotype with mosaicism for a ring chromosome 20 [r(20) ( $\mathrm{p} 13 \mathrm{q} 13.3)]$. Fluorescence in situ hybridization (FISH) with 20pTel/qTel probes (Cytocell, Cambridge, UK) showed a fusion signal on the ring (figure, C) consistent with the absence of terminal deletion(s). The red and green signals contributing to the fusions were examined carefully, and their patterns were not suggestive of a complex rearrangement at the fusion site. In total, 23 of 139 (16.5\%) metaphases had a ring; 1 cell had a double ring and loss of the ring was not observed. Genomic microarray analysis using the $4 \times 180 \mathrm{~K}$ Oligonucleotide Array platform (Agilent Technologies, Santa Clara, CA) did not detect imbalances on chromosome 20 (probes spanning genomic coordinates chr20:8,741-62,379,037 [hg18]), which corroborated the subtelomeric FISH results. However, a $931-\mathrm{kb}$ deletion at $16 \mathrm{p} 13.11$ was identified (nucleotide positions 15,507,164 to 16,438,224; hg18). Additional FISH using clone RP11-585P8 confirmed the deletion at 16p13.1 in 200 interphase nuclei and 13 metaphases, with 3 metaphases showing both the r(20) and the hemizygous interstitial 16p13.11 deletion. Neither of the patient's parents had the ring chromosome or the 16p13.11 microdeletion.

Discussion. Ring chromosome 20 is a genetic syndrome characterized by a childhood- or adolescentonset epileptic encephalopathy in a previously developmentally normal child. ${ }^{1,2}$ Since its original description in 1972, more than 100 cases have been reported. ${ }^{1}$ Ring chromosome 20 is usually sporadic, with no ethnic or sex predilection. ${ }^{3}$

Epilepsy is an almost invariant feature of $\mathrm{r}(20)$ and is usually medically refractory. ${ }^{1-3}$ Complex partial seizures arising from the frontal lobes are the most common seizure semiology and frequently present as nonconvulsive status epilepticus. Nocturnal frontal lobe seizures with tonic posturing, hyperkinetic behaviors, or subtle arousal-like behaviors are well described. ${ }^{1-3}$

Cognition is usually normal before the onset of seizures but regresses in proportion to the severity of the epilepsy and can become markedly impaired. ${ }^{1}$ Behavioral changes have also been reported. ${ }^{3}$ Ring chromosome 20 is only rarely associated with dysmorphic features, and these are usually subtle. ${ }^{1-3}$

Conventional structural MRI is usually normal. ${ }^{2,3}$ In the interictal EEG, background may be normal to mildly slow and there may be focal interictal epileptiform discharges, often in the frontal brain regions. Epileptiform activity may be activated in sleep. The ictal EEG demonstrates diffuse, frontally predominant slow waves with intermixed spikes or sharp waves, creating a distinctive notched appearance. ${ }^{1-3}$

In patients with mosaic $\mathrm{r}(20)$, the extent of mosaicism in lymphocytes is variable and has been correlated with age at epilepsy onset and epilepsy severity. ${ }^{1,4}$ As in all mosaic disorders, the degree of mosaicism in other tissues such as brain may not be 
A

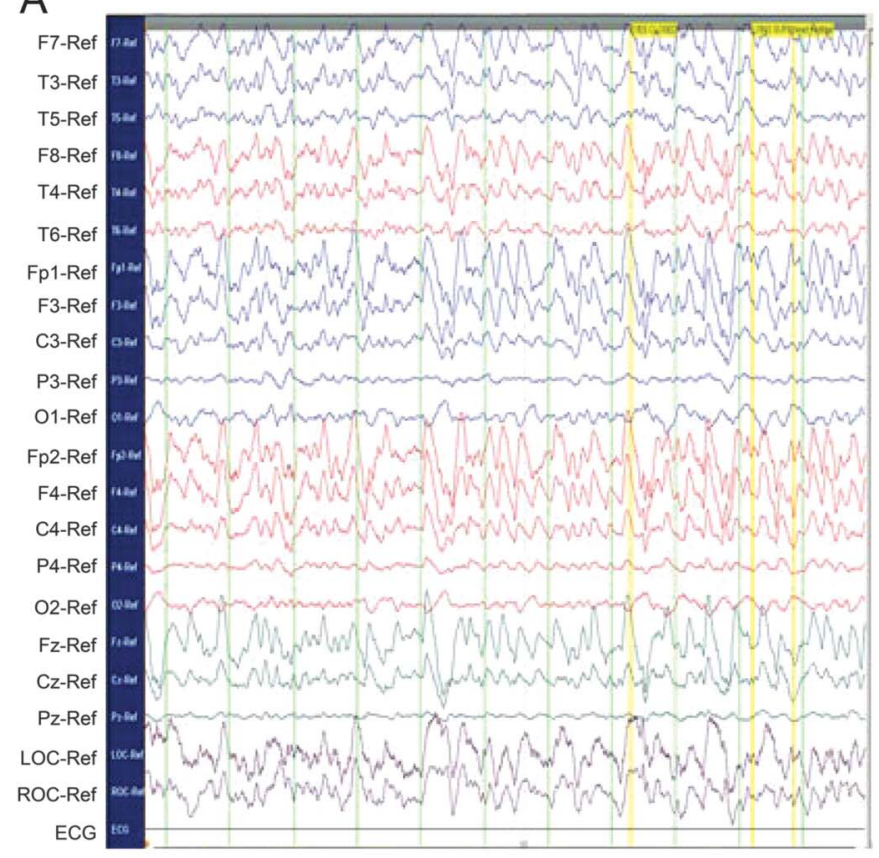

B

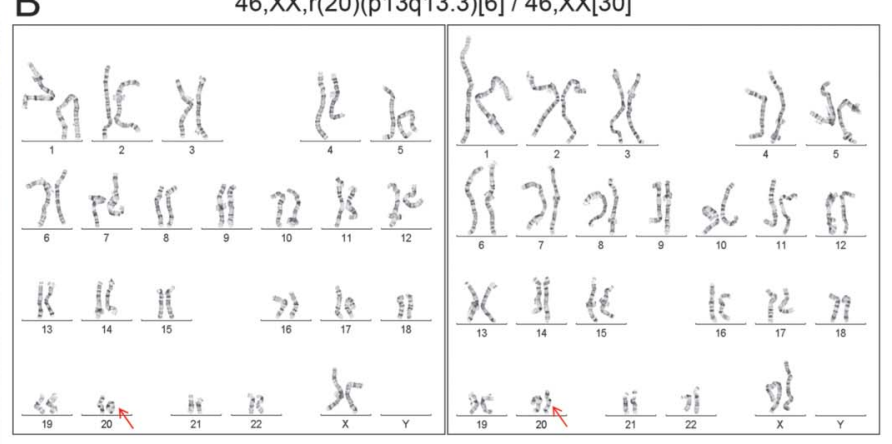

C
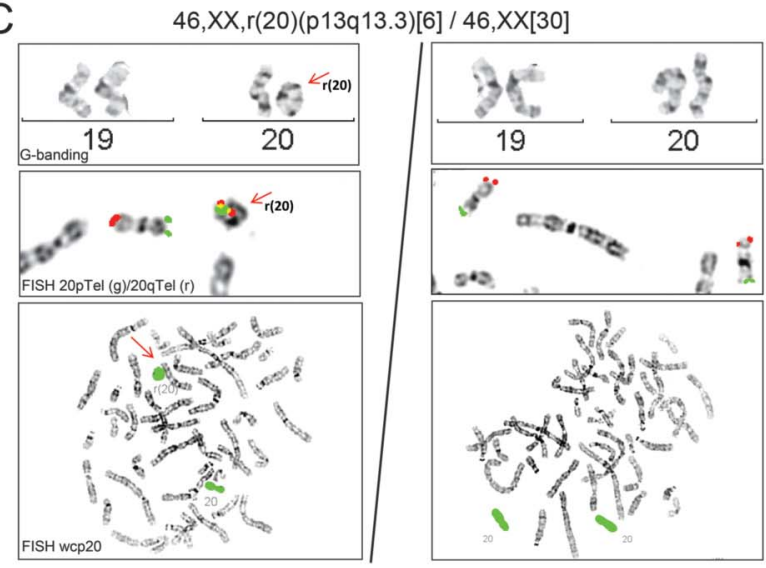

(A) Referential montage (Pz reference) demonstrating frontal theta frequency activity evolving into 3- to 4-Hz frontal, sharply contoured, semirhythmic slow waves. This pattern was associated with alteration of consciousness and drowsiness. (B) Karyotype demonstrating mosaicism of ring chromosome 20 ; some cells have the ring chromosome, whereas others have 2 normal chromosomes 20 (arrows). (C) Fluorescence in situ hybridization (FISH) with 20pTel/qTel probes (Cytocell, Cambridge, UK) showed a fusion signal on the ring suggestive of absence of terminal deletion(s).

accurately reflected by blood levels. It is possible that such tissue-specific mosaicism, particularly as it relates to brain, may also contribute to the variable expressivity of this disorder.

Patients with $\mathrm{r}(20)$ fall into 2 groups, namely those with and without accompanying chromosome 20 telomeric deletions. The patients with deletions can be detected with microarray if the level of mosaicism is high enough to detect copy number change on the microarray platform. ${ }^{4}$ Those without deletions require conventional cytogenetic procedures such as G-band analysis for diagnosis. At least 50 cells, and potentially up to 100 cells, may need to be analyzed to detect low-level mosaicism for the ring. ${ }^{3}$

In our reported patient, the absence of detectable subtelomeric DNA loss on microarray is consistent with the subtelomeric FISH results that did not show evidence of a deletion. However, our patient had a low degree of mosaicism r(20) in blood (16.5\%), which is near the limit of detection of mosaic copy number variations by this microarray platform (10\%-20\%). Therefore, the presence of a small mosaic deletion distal to the subtelomeric FISH probes cannot be ruled out. In addition, karyotype is derived from dividing lymphocytes, whereas DNA for microarray is obtained from all nucleated white blood cells, with neutrophils normally representing the most predominant cell type and thus the DNA source. It is theoretically possible that the ring is absent or at a lower level of mosaicism in neutrophils and thus that the ring was underrepresented on the microarray compared to the karyotype, precluding the identification of copy number changes in the mosaic ring chromosome.

The etiology of epilepsy in $\mathrm{r} 20$ syndrome has not been elucidated. The CHRNA4 and KCNQ2 genes, both associated with autosomal dominant epilepsy syndromes (nocturnal frontal lobe epilepsy and KCNQ2-related epilepsy syndromes, respectively), are both located at the 20qter. It has been postulated that the epilepsy in r20 may result from abnormal regulation of these genes due to positional effects from the ring, such as silencing from tandem repeats of telomeric DNA. ${ }^{5}$

16p13.11 is a newly described genomic hotspot for deletions and duplication. Deletions at 16p13.11 are associated with schizophrenia, autism, mental retardation, attention-deficit/hyperactivity disorder, and pleiomorphic epilepsy phenotypes. ${ }^{6}$ This locus has 
recently been suggested as the single most prevalent genetic risk factor for epilepsy identified to date. ${ }^{6}$ There does not seem to be an ethnic predisposition. ${ }^{6}$ One large European series of 3,812 patients with epilepsy (focal and generalized) and 1,299 healthy controls found the prevalence for the 16p13.11 deletion in patients with epilepsy to be $0.6 \% .^{6}$ Some cases of 16 p13.11 appear to be de novo; in inherited cases, parents seem to be unaffected by epilepsy, suggesting a role for modifier genes or environmental factors. ${ }^{6}$ Epilepsy phenotypes, including treatment response, are highly variable. ${ }^{6}$ Various congenital anomalies, microcephaly, and cortical malformations have been described but are not consistent or obligate. ${ }^{6}$ There seems to be a common deletion size in patients with epilepsy harboring the 16p13.11 deletion spanning a number of genes, including NDE1, MYH11, ABCC1, and $A B C C 6{ }^{6} N D E 1$ interacts with the LIS1 gene, which is implicated in neuronal migration, making it a logical candidate gene ${ }^{7}$; however, 1 study examining cortical pathology in NDE1 haploinsufficiency failed to demonstrate any gross cytoarchitectural changes in the cortex in a series of patients with epilepsy. ${ }^{7}$

Our case serves to highlight 2 very important chromosomal anomalies associated with epilepsy that happen to coincide in the same patient. Our patient's unique epilepsy phenotype, including subclinical status epilepticus and the specific appearance of the ictal EEG, closely fits the ring chromosome 20 phenotype, and our ability to diagnose her correctly was rooted in her neurologic presentation. It is, however, possible that the 16p13.11 deletion is acting as a disease modifier and influencing the severity of her epilepsy. This case highlights the need to perform G-banded karyotype in children with intractable epilepsy not easily explained by small genomic deletions or duplications. It also exemplifies the increasing recognition of multiple genetic lesions interacting to determine phenotype in a single patient with epilepsy.

From the Hospital for Sick Children, University of Toronto, Ontario, Canada.

Author contributions: Lance H. Rodan: drafted the initial manuscript and reviewed and revised the manuscript. Maria Zak: contributed to discussion and critical revision of the manuscript. Ann M. Joseph-George: contributed to discussion and critical revision of the manuscript. James Stavropoulos: contributed to discussion and critical revision of the manuscript. Berge A. Minassian: contributed to discussion and critical revision of the manuscript and acted as the supervisor.

Study funding: This work was supported by Genome Canada, The Ontario Brain Institute, and The McLaughlin Foundation.

Disclosure: Lance H. Rodan reports no disclosures. Maria Zak has received travel funding from Eisai, has been an employee of Think Research, and has been a consultant for HeadCan. Ann M. JosephGeorge and James Stavropoulos report no disclosures. Berge A. Minassian holds patents for diagnostic testing of the following genes: EPM2A, EPM2B, MECP2, and VMA21; has received license fee payments and royalty payments from patents for diagnostic testing of the following genes: $\mathrm{EPM} 2 \mathrm{~A}, \mathrm{EPM} 2 \mathrm{~B}, \mathrm{MECP} 2$, and VMA21; has received research support from Genome Canada, The Ontario Brain Institute, and The McLaughlin Foundation; and holds the University of Toronto Michael Bahen Chair in Epilepsy Research. Go to Neurology.org/ng for full disclosure forms. The Article Processing Charge was paid by the authors.

This is an open access article distributed under the terms of the Creative Commons Attribution-NonCommercial-NoDerivatives License 4.O (CC BY-NC-ND), which permits downloading and sharing the work provided it is properly cited. The work cannot be changed in any way or used commercially.

Received June 7, 2015. Accepted in final form November 17, 2015.

Correspondence to Dr. Rodan: lancerodan@gmail.com

1. Daber RD, Conlin LK, Leonard LD, et al. Ring chromosome 20. Eur J Med Genet 2012;55:381-387.

2. Elens I, Vanrykel D, De Waele L, et al. Ring chromosome 20 syndrome: electroclinical description of six patients and review of the literature. Epilepsy Behav 2012;23:409-414.

3. Radhakrishnan A, Mennon RN, Hariharan S, Radhakrishnan K. The evolving electroclinical syndrome of "epilepsy with ring chromosome 20". Seizure 2012;21: 92-97.

4. Conlin LK, Kramer W, Hutchinson AL, et al. Molecular analysis of ring chromosome 20 syndrome reveals two distinct groups of patients. J Med Genet 2011;48:1-9.

5. Giardino D, Vignoli A, Ballarati L, et al. Genetic investigations on 8 patients affected by ring 20 chromosome syndrome. BMC Med Genet 2010;11:146.

6. Heinzen EL, Radtke RA, Urban TJ, et al. Rare deletions at 16p13.11 predispose to a diverse spectrum of sporadic epilepsy syndromes. Am J Hum Genet 2010;86:707-718.

7. Liu JY, Kasperaviciute D, Martinian L, et al. Neuropathology of 16p13.11 deletion in epilepsy. PLoS One 2012;7: e34813. 


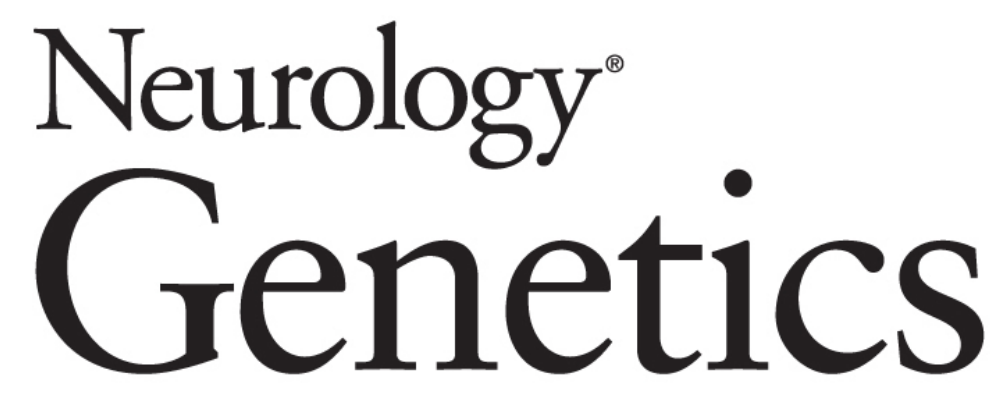

Co-occurrence of 16p13.11 microdeletion and ring chromosome 20 syndrome Lance H. Rodan, Maria Zak, James Stavropoulos, et al. Neurol Genet 2016;2;

DOI 10.1212/NXG.0000000000000043

\section{This information is current as of January 14, 2016}

\section{Updated Information \&} Services

\section{References}

Subspecialty Collections

Permissions \& Licensing

\section{Reprints}

including high resolution figures, can be found at: http://ng.neurology.org/content/2/1/e43.full.html

This article cites 7 articles, 1 of which you can access for free at: http://ng.neurology.org/content/2/1/e43.full.html\#\#ref-list-1

This article, along with others on similar topics, appears in the following collection(s):

All Epilepsy/Seizures

http://ng.neurology.org//cgi/collection/all_epilepsy_seizures All Genetics

http://ng.neurology.org//cgi/collection/all_genetics

Information about reproducing this article in parts (figures,tables) or in its entirety can be found online at:

http://ng.neurology.org/misc/about.xhtml\#permissions

Information about ordering reprints can be found online: http://ng.neurology.org/misc/addir.xhtml\#reprintsus

Neurol Genet is an official journal of the American Academy of Neurology. Published since April 2015, it is an open-access, online-only, continuous publication journal. Copyright (C) 2016 American Academy of Neurology. All rights reserved. Online ISSN: 2376-7839.

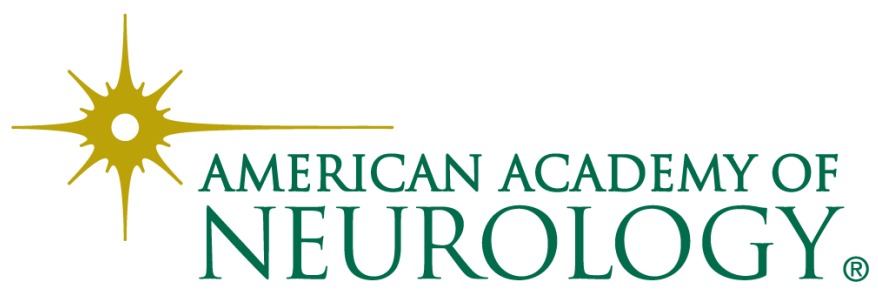

